\title{
Technology Readiness for the System of Rice Intensification (SRI)
}

\author{
Mohamad Faizal Ahmad Zaidi \\ School of Technology Management \& Logistics \\ Collage of Business, Universiti Utara Malaysia, Sintok 06010, Kedah Darulaman Malaysia \\ Email: mdfaizal@uum.edu.my \\ Siti Norezam Othman \\ School of Technology Management \& Logistics \\ Collage of Business, Universiti Utara Malaysia, Sintok 06010, Kedah Darulaman Malaysia
}

\author{
Noor Hidayah Abu \\ School of Technology Management \& Logistics \\ Collage of Business, Universiti Utara Malaysia, Sintok 06010, Kedah Darulaman Malaysia
}

DOI: 10.6007/IJARBSS/v6-i1/1984 URL: http://dx.doi.org/10.6007/IJARBSS/v6-i1/1984

\begin{abstract}
A system of rice intensification (SRI) was conceptualised as a system of formulated principles for producing rice rather than a technical practices of technology. However, with the advancement of technology, numerous studies have focused on the adoption issues of rice intensification technology (RIT) for SRI. Although it is important to questions what motivate, and what inhibit farmers from adopting RIT, there were few studies had actually addressed these questions from the perspective of technology readiness. This article aims to explain how the benefits and barriers in SRI influence the readiness of RIT, prior to its adoption. As a result, a framework was proposed under the domain of technology readiness to explain how the readiness of RIT could be affected by both motivators and inhibitors in SRI. It can be used to characterise and examine the extent to which motivators or inhibitors of RIT existed in the process and influenced the advancement of SRI. This implicates the researchers in SRI would be able to screen and identify technological problems relating to adoption issues of RIT for SRI, and taking relevant actions to contend with the identified problems. This article has promoted SRI as not being antitechnology, which means with the right management of technology, RIT can be used to achieve the principles of SRI for better water management, seedling, and transplanting.
\end{abstract}

KEYWORDS: Rice intensification technology (RIT); sustainability; system of rice intensification (SRI); technology management; technology readiness

JEL Classification: 032; Q160 


\subsection{Introduction}

With the advancement of science and technology, a conventional system to intensify the agricultural outputs was created to fulfil increasing demand on foods. Although this conventional system has multiplied the yielding, it has adverse consequences to the environment (e.g., chemical fertiliser) (Matson, Parton, Power, \& Swift, 1997). As a result, a new system that can intensify the production, but at the same time also environmental friendly is needed. As such, a system of rice intensification (SRI) was introduced. SRI was originally designed to improve local rice production in the area that have problem with water irrigation (de Laulanié, 2011). Although the basic principles of SRI are only focused on transplanting of young seedling and management of water irrigation, the innovation to practice these principles are still growing, progressing, and far from being completed (Uphoff, 2008). As such, it was suggested "major scientific breakthroughs must occur [...] to achieve the ecological intensification that is needed to meet the expected increase in food demand" (Cassman, 1999, p. 5952). This implies the practices of SRI can be improved with the innovation in technology to achieve intensification of rice production. Meanwhile, it was found that despite of the benefits in SRI, it still faces up with some adoption issues. To improve the adoption rate of SRI, it was argued that a better rice intensification technology (RIT) could be needed. This was highlighted by the recent literatures on the importance of acquiring improved technologies to increase rice production (Katambara, et. al., 2013; Ragasa, et. al., 2013). For these reasons, this study aims to build a framework to demonstrate the linkages between the adoption issues in SRI and RIT with the concept of technology readiness.

\subsection{Problem Statement, Research Question, and Objective}

$\mathrm{SRI}$ is generally conceptualised as a system of formulated principles for production of rice rather than a technical practices of technology (Namara, Weligamage, \& Barker, 2003). SRI also differs from the technologies promoted in the recent years for paddy agriculture (Uphoff, 2008). However, the basic principles of SRI have been practised as early as 1950s (Uphoff, 2006), and some of the principles were indifferent from conventional system (Barrett \& Moser, 2002). As such, although SRI was referred to as "an ideal low-external input sustainable agriculture (LEISA) technology" (Barrett \& Moser, 2002, p. 2), it was found that the methods used in SRI were derived more toward tradition than technology (Uphoff, 2006). In the meantime, with the advancement of technologies, recent studies have shown interest and have focused on the adoption issues of RIT for SRI (e.g., Dontsop-Nguezet, Diagne, Okoruwa, \& Ojehomon, 2011; Ragasa, et. al., 2013). For instance, a study has found that a lack of training on new technology was one of major problems to adopt SRI by farmers (Devi \& Ponnarasi, 2009). This implies RIT would have contributed to the advancement of SRI, but could not be implemented because of the existed barriers in SRI. For this reason, it is important to questions what motivate and what inhibit farmers from adopting RIT for SRI. With few studies had actually addressed these questions from the perspective of technology readiness, this article aims to explain how the benefits and barriers in SRI influence the readiness of RIT for adoption of SRI. This can be achieved by building a framework with the concept of motivators and inhibitors from technology readiness (Parasuraman \& Colby, 2015). 


\subsection{Reviews on System of Rice Intensification}

Previous study has found the failure of conventional agriculture systems was contributed by the (1) production of rice that are not localised, (2) expensive inputs such as chemical and energy, (3) imbalance between food consumption and resources, and (4) ineffective distribution of foods (Tittonell, 2013). To cope with this situation, a green method for sustaining the ecosystem, yet increasing production of food and improving livelihoods is needed (Cassman, 1999; Carswell, 1997; Matson, Parton, Power, \& Swift, 1997). As a result, SRI that uses less water, seed, and external inputs has started to gain popularity (Barrett \& Moser, 2002). SRI can be referred to as "a strategy of irrigated rice production, adapted to local conditions, that alters plant, soil, water and nutrient management practices" (Uphoff, 2006, p. 3). SRI is different from the conventional agriculture systems since its basic principles are to use minimal water irrigation, and transplanting of young seedling (de Laulanié, 2011). It was found that while the conventional agriculture systems have failed to supply sufficient food to the world (Tittonell, 2013), SRI was claimed to improve food sustainability (e.g., Badgley, et. al., 2007; Katambara, et. al., 2013; Kumar, et. al., 2012; Vijayakumar, Ramesh, Chandrasekaran, \& Thiyagarajan, 2006) by increasing the productivity of rice production, and also sustaining the natural environment (Styger, Aboubacrine, Attaher, \& Uphoff, 2011). Since the input-side innovation in SRI is still in progress (Uphoff, 2008), this article defines SRI as a set of technical practices to intensify rice production by applying the principles that ranged from "seed sorting, sowing, transplanting younger seedlings, weeding, and water management" (Katambara, et. al., 2013, p. 370).

Previous studies have shown that SRI was able to improve returns on cost (Devi \& Ponnarasi, 2009), doubling the profits (Namara, Weligamage, \& Barker, 2003), and achieving more than double of yields over conventional systems (Karki, 2010). Besides of these positive outcomes, SRI was also found to have many benefits. For instance, a study has found that higher grain and yield, reduced requirement of seeds, and less use of water were rated as the main benefits of SRI (Devi \& Ponnarasi, 2009). These benefits should be able to ease the adoption process of SRI. Unfortunately, despite of many possible benefits, they might have not been studied appropriately (Karki, 2010). Table 1 shows the potential benefits of SRI that deserve further attention. 
Table 1: The benefits of SRI

\begin{tabular}{cll}
\hline No. & Criteria & Sources \\
\hline 1. & SRI produces more yield & \\
2. & SRI produces more tillers & \\
3. & SRI produces more milling output & \\
4. & SRI has less disease & \\
5. & SRI has less pest attack & \\
6. & SRI has less lodging of rice & Devi and Ponnarasi (2009); \\
7. & SRI uses less labour for harvesting & Namara, Weligamage, and Barker \\
8. & SRI uses less labour for transplanting & (2003) \\
9. & SRI uses less labour for bound construction & \\
10. & SRI uses less labour for bound cleaning & \\
11. & SRI reduces demand for herbicide & \\
12. & SRI reduces demand for inorganic fertiliser & \\
13. & SRI reduces input costs & \\
14. & SRI saves water & \\
15. & SRI saves seed & \\
16. & SRI improves seed quality & \\
17. & SRI is environment-friendly & \\
\hline
\end{tabular}

Despite positive outcomes of SRI, the adoption is inconsistent and spreading slow across various regions (Styger, Aboubacrine, Attaher, \& Uphoff, 2011). This implies there could also be some barriers for adoption of SRI. For instance, a study has found that lacks of skilled labour, awareness, and training were rated as the major problems for adoption of SRI (Devi \& Ponnarasi, 2009). In addition, it was argued that although the benefits of SRI can be easily obtained, it seems that some adopters were simply unable to accept and unwilling to try it out (Uphoff, 2006). In the context of this study, these problems are the possible barriers for SRI. Table 2 summarises the potential barriers that can possibly neutralise the benefits of SRI.

Table 2: The barriers of SRI

\begin{tabular}{cll}
\hline No. & Criteria & Sources \\
\hline 1. & SRI requires well-drained soils & \\
2. & SRI requires skilled labour for management & \\
3. & SRI requires more effort for implementation & \\
4. & SRI has mice/pests attack due to unclean bunds & \\
5. & SRI does not work on flooded fields & Rao (2011); \\
6. & Transplanting is difficult in SRI & Devi and Ponnarasi (2009); \\
7. & Transplanting requires special skills for SRI & Namara, Weligamage, and Barker \\
8. & Transporting organic matter is problematic in SRI & (2003) \\
9. & Lack of awareness on importance of SRI & \\
10. & Lack of extension service for SRI & \\
11. & Nursery management is complicated for SRI & \\
12. & Alternate wetting and drying is not easy for SRI & \\
13. & Organic matter/manure not easily available for SRI & \\
14. & Not easy to control weed for SRI & \\
\hline
\end{tabular}

In the context of technology readiness, both benefits and barriers in SRI can be treated as motivators and inhibitors, respectively. For the purpose of this article, motivators refer to the benefits in SRI that might improve the readiness of RIT for adoption, while inhibitors refer to the barriers in SRI that might reduce the readiness of RIT for adoption. 


\subsection{Reviews on Rice Intensification Technology}

Intensification refers to "the increase in the value of output per hectare", which can be achieved with farming technology (Tiffen, Mortimore, \& Gichuki, 1994, p. 96). Despite technology for rice intensification have been around for long time, "the choice-of-technology issue in rice is, however, not simply a question of choice between technologies $X$ and $Y$ " (von Braun, Puetz, \& Webb, 1989, p. 104). This observation is still true today since the literature on $\mathrm{SRI}$ is dominated by the issues on technology adoption (e.g., Dontsop-Nguezet, Diagne, Okoruwa, \& Ojehomon, 2011; Ragasa, et. al., 2013). This happens due to technological change could affect the production of rice at the input-side, such as seed, fertiliser, irrigation, and labour (von Braun, Puetz, \& Webb, 1989). Since these input-sides of rice production are fundamental to the principles of SRI, it is timely relevant to discuss the issues on RIT for SRI.

The techniques for SRI are rather "a set of ideas" than a "fixed prescriptions" (Uphoff, 2008). As such, even though the basic principles of SRI are agreed upon water irrigation, and young seedling, the complimentary techniques for its implementation are not (de Laulanié, 2011). In another words, although the practises of SRI can be summarised into (1) the use of young seedlings, (2) trauma avoidance to the roots, (3) optimal wide spacing for the plants, (4) sufficiently moist of soils, (5) active aerate of soils, and (6) enhancement of soil organic matter, the actual practices can be varied according to adaptation and extension of use (Uphoff, 2008). As a result of slight variations in the implementation of SRI, various studies have commonly addressed SRI with some (if not all) combination of techniques as shown in Table 3. This table summarised eleven common techniques to practice SRI (not necessarily in a sequence order) from the relevant literatures between 2003 and 2013 .

Table 3: Technologies or techniques for SRI

\begin{tabular}{|c|c|c|}
\hline No. & Criteria & Sources \\
\hline 1. & $\begin{array}{l}\text { SRI uses land/field preparation technique } \\
\text { (e.g. to activelv aerate the soil) }\end{array}$ & \multirow{11}{*}{$\begin{array}{l}\text { Ragasa, et. al. (2013); } \\
\text { Dontsop-Nguezet, Diagne, Okoruwa, } \\
\text { and Ojehomon (2011); } \\
\text { Uphoff }(2008,2006) ; \\
\text { Lampayan, et. al. (2004); } \\
\text { Namara, Weligamage, and Barker } \\
\text { (2003) }\end{array}$} \\
\hline 2. & $\begin{array}{l}\text { SRI uses spacing/row planting technique } \\
\text { (e.g., for plants optimal wider spacing) }\end{array}$ & \\
\hline 3. & $\begin{array}{l}\text { SRI uses transplanting technique } \\
\text { (e.g., to avoid trauma to the roots) }\end{array}$ & \\
\hline 4. & $\begin{array}{l}\text { SRI uses seed priming/seeding technique } \\
\text { (e.g., with the use of young seedlings) }\end{array}$ & \\
\hline 5. & $\begin{array}{l}\text { SRI uses hybrid rice varieties and seed } \\
\text { (e.g., that able to save seed) }\end{array}$ & \\
\hline 6. & $\begin{array}{l}\text { SRI uses specific type of fertiliser } \\
\text { (e.g., to enhance soil organic matter) }\end{array}$ & \\
\hline 7. & $\begin{array}{l}\text { SRI uses fertilisation technique } \\
\text { (e.g., rate, method, timing of application) }\end{array}$ & \\
\hline 8. & $\begin{array}{l}\text { SRI uses herbicide resistant rice technique } \\
\text { (e.g., for land preparation, weed control method) }\end{array}$ & \\
\hline 9. & $\begin{array}{l}\text { SRI uses seeding technique } \\
\text { (e.g., mulch, pull, dig, chop, etc. besides herbicide) }\end{array}$ & \\
\hline 10. & $\begin{array}{l}\text { SRI uses irrigation technique } \\
\text { (e.g., to supply/keep paddy soil sufficiently moist) }\end{array}$ & \\
\hline 11. & $\begin{array}{l}\text { SRI uses water saving technique } \\
\text { (e.g., technique not to waste water, besides irrigation) }\end{array}$ & \\
\hline
\end{tabular}


Based on Table 3, although the basic principles of SRI are stressed upon water irrigation and young seedling, the RIT to further enhance and complement these basic principles have not been finalised (de Laulanié, 2011), which implies the techniques to implement SRI were slightly varied across regions, climates, and/or practitioners. For instance, while a study in Tamil Naidu has transplanted young seedling of 8 to 12 days (Barah, 2009), it was between 8 to 15 days in the early study in Madagascar (Stoop, Uphoff, \& Kassam, 2002). This happens due to the innovation in SRI is still an on-going processes (Uphoff, 2008). This also implies the best practices for SRI is yet to be found. Since the RIT for SRI can be ranged from a field preparation technique all the ways to water management technique (as shown in Table 3), it is worth to investigate all of these techniques for better understanding of SRI. For the purpose of this article, RIT refers to a set of input-related techniques in SRI to intensify the production of rice.

\subsection{A Framework}

Innovation in SRI is not originated from the scientific discovery, yet it comes from the nonscientific community, i.e. farmers (Uphoff, 2008). For this reason, this article has focused on a person's adoption issue of SRI with the concept of technology readiness in mind. For the purpose of this article, technology readiness should be referred to as a person (i.e., farmer) propensity to use new technology (i.e. RIT) to accomplish an existing task (i.e. the principles of SRI). Since the concept of technology readiness involves a set of motivators and inhibitors, this article has treated the benefits in SRI as a source of motivators, while the barriers as a source of inhibitors. This concept is referred to for building of framework since the constructs for technology readiness will continue to grow according to innovation (i.e. innovation in SRI). Due to the motivators attract a person readiness to technology, while the inhibitors detract a person readiness from technology (Parasuraman \& Colby, 2015), a framework as shown in Figure 1 was proposed. This framework has conceptualised that although the benefits in SRI can motivate farmers to adopt RIT, the barriers, in another way around can inhibit them from adopting it. Simply speaking, while the benefits of SRI increase the readiness of RIT for adoption, the barriers decrease the readiness. In the meantime, both benefits and barriers could co-influence the readiness of RIT where the differences in strengths between them will determine the adopters' final readiness to adopt RIT for SRI.

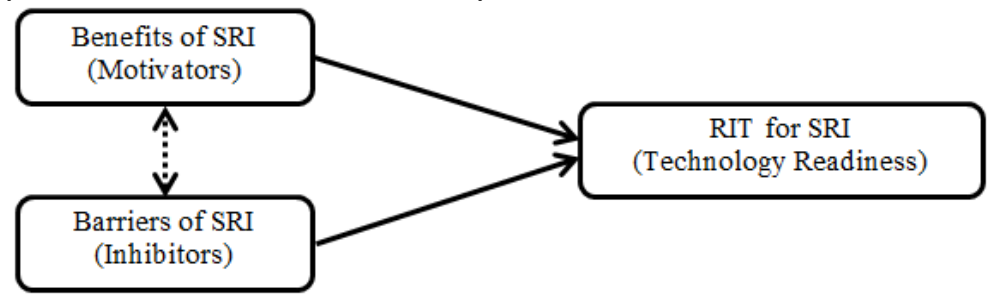

Figure 1: A framework of technology readiness for SRI

\subsection{Discussions}

The concept of technology readiness "was anchored in literature on adoption of new technologies and people-technology interactions" (Parasuraman \& Colby, 2015, p. 60). With this in mind, it was clear that the concept of technology readiness is highly relevant to discuss the adoption issue of farmers on RIT for SRI. As such, since technology can be referred to as 
tools, processes, methods, and systems (Khalil, 2000), this article has treated the technologies for rice intensification (i.e. RIT) as manifested by the principles of SRI. In another words, although SRI is conceived as a methodological rather than technological principles (Uphoff, 2008), the adoption issue of SRI can be discussed in the context of technology readiness (in this case the readiness of RIT for SRI). As a result, all criteria for motivators and inhibitors of RIT were adapted directly from the lists of benefits and barriers of SRI, while the techniques for RIT were adapted from the practices of SRI.

As shown in Figure 1, the framework has suggested that the readiness of RIT can be influenced either individually or in combination of both motivators and inhibitors of SRI. By studying the interactions between motivators, inhibitors, and RIT, this framework has potentially unveiled several ways to improve the adoption of SRI with the management of technology. Firstly, this framework has shown that the adoption of RIT can be managed by manipulating the motivators and inhibitors of technology readiness, either by maximising the benefits or minimising the barriers in SRI. For instance, technology can be managed by identifying the specific types of benefits in SRI that are positively related to the specific techniques in RIT, in which through the management of these techniques, the related benefits can be enhanced. Similarly, by identifying the specific types of barriers that are negatively influenced the specific techniques in RIT, the negative effects of these barriers can be minimised by improving of these related techniques. As a result, the critical techniques in RIT that need to be improved can be readily pinpointed according to the related benefits and/or barriers rather than trying hard to hit the unknown target. Hence, by managing of these critical techniques, the benefits or barriers related to these techniques can also be managed. Therefore, the readiness of RIT for adoption of SRI can be increased.

Secondly, based on the literature of technology management, there are various classifications of technologies, namely new technology, emerging technology, high technology, low technology, medium technology, and appropriate technology. Specifically, the appropriate technology that refers to an optimal fits between technology and resources needed to use it (Khalil, 2000) should be ideal for RIT for better adoption of SRI. Thus, it is expected through the empirical investigation of this framework (which should be performed in near future), detail results should enable us to identify the appropriateness of technologies in RIT that could be related to their level of readiness for adoption. In another words, further analysis on this framework should enable us to identify various classes of technologies so that they can be managed accordingly. This will allow new technologies that yet to be appropriated for RIT, but a lot easier to perform and able to deliver similar result to the existing one should be targeted for appropriation for easy adoption of SRI.

Thirdly, in order to increase the adoption of SRI, it will be worth to look at the traits of adopters of technologies. According to the concept of technology readiness, optimism and innovativeness are the two traits for motivators, while discomfort and insecurity are the two traits for inhibitors (Parasuraman \& Colby, 2015). Although the proposed framework does not dig further into these traits, this framework has provided a platform to investigate the traits as they attached to both motivators and inhibitors. In another words, managing technology readiness for SRI can be more effective by knowing the relevant traits behind the related 
benefits or barriers that influenced the adoption of RIT for SRI. For instance, by investigating what makes the adopters becoming optimistic on the benefits (motivators) of SRI will enable action to be taken to enhance these traits. Details analysis on the traits can be done after investigating the elements for the motivators, inhibitors, and RIT as suggested in the framework. As such, this framework allows investigation of not only the influences of motivators and inhibitors toward RIT for SRI, but also can be extended to investigate the traits attached to both motivators and inhibitors for better understanding of RIT readiness for adoption of SRI.

Meanwhile, since "we need new science to contribute to the design of knowledge-intensive systems such as organic farming, which relies more on process- than on input-based technologies" (Tittonell, 2013, p. 32), it appeared that the techniques for SRI could be improved further in term of process technology for ease of adoption. For instance, a low-cost water saving technology (a technique under RIT) to increase irrigation productivity that was tested in the Philippine is focused on the process (Lampayan, et. al., 2004). In summary, the framework proposed in this article that shows the interactions between motivators and inhibitors of SRI on the readiness of RIT is enabled us to manage the readiness of technologies for rice intensification. This implies the adoption of SRI can be potentially improved by manipulating the related technologies in RIT according to the motivators or inhibitors that influenced them. Similarly, the technologies in RIT can be better adopted by the adopters if the motivators or inhibitors of the said technologies for SRI were identified and able to be manipulated.

\subsection{Implications}

This framework of RIT readiness for SRI has brought at least four implications. Firstly, despite many literatures that have stressed upon the adoption issues of SRI, this article was among the few that focused on the technology readiness in SRI prior to adoption itself. As such, this article has contributed to the literature of SRI by highlighting the possibility of issues that could be caused by the unfamiliarity of farmers on the technologies applied for SRI. Secondly, although this article was inspired by the domain of technology readiness, all criteria for the motivators, inhibitors, and RIT were adapted from the relevant literature of SRI, which has personalised the concept of technology readiness for SRI. In other words, these criteria can be readily used as a list to characterise and examine the extent to which motivators or inhibitors of RIT existed in the process and influenced the advancement of SRI. Thirdly, with the knowledge on what influences technology readiness for SRI, researchers would be able to screen and identify technological problems relating to adoption issues of SRI. This will also enable them to think of the relevant actions to contend with the identified problems. And last but not least, this framework has promoted SRI as not being anti-technology, which means with the right management of technology, RIT can be used to achieve the principles of SRI for better water management, seedling, and transplanting.

\subsection{Limitations}

This article was identified with the following limitations. Firstly, the listed criteria for moderators, inhibitors, and RIT were adapted from the recent empirical studies in SRI, which 
means these lists were not a result of thorough scientific literature review. As such, the representativeness of these criteria to the variables is arguable. Secondly, this article was presented from the domain of technology readiness, in which the discussion was purposely limited to the scope of technology. Hence, there could be other critical factors surrounding the issue addressed here, but purposely ignored for being irrelevant to the context of this article. Lastly, this article was using a simplified version of technology readiness as an early effort to relate technology with SRI. Therefore, the specific components of technology readiness for motivators (i.e. optimism and innovativeness), and inhibitors (i.e. discomfort and insecurity) were not discussed. To summarise, since the values of the proposed framework are somehow limited due to no scientific evidences to support the discussions, this article should be interpreted within the context of its own, as a framework.

\subsection{Recommendations}

This framework should be further investigated to verify its functionality. In this case, all variables, i.e. the motivators, inhibitors, and RIT for SRI should be examined to confirm on their validity and reliability. To do this, an empirical study needs to be performed. For a start, a preliminary study is currently underway to examine this framework, which is crucial not just to verify the measurement items of all variables, and to test the relationships between motivators, inhibitors, and RIT for SRI, but also to demonstrate the concept of technology readiness regarding the adoption issue in SRI.

\subsection{Conclusions}

The idea for this article has come from the adoption issue of SRI focusing on the advancement of innovation in RIT. Although this adoption issue is relevant to be addressed in the context of technology readiness, very few published works were known to have done so. As a result, a framework to representatively explain the influences of motivators and inhibitors from the concept of technology readiness on RIT for SRI was proposed. This framework has suggested that both motivators and inhibitors should be seen through the benefits and barriers in SRI, respectively, which can influence a farmer's readiness to adopt and implement RIT for SRI. Besides that, motivators and inhibitors could co-exist to influence RIT readiness for SRI. In this case, the differences in strengths between them will influence a farmer's final readiness to adopt RIT. Meanwhile, from the perspective of technology management, knowing the interactions between them will allow farmers (or decision makers) to better manage various technologies for SRI according to the relevant motivators and/or inhibitors, hence improving the RIT readiness for SRI. This article has contributed to the literature of technology readiness by demonstrating its application in the adoption issue of RIT for SRI. This article also contributes to better understanding of the criteria for motivators, inhibitors, and RIT. However, the use of this framework is limited by the scope of study, which only discusses the adoption issue from the perspective of technology readiness. As such, the criteria discussed here for motivators, inhibitors, and RIT might not be exhaustive and inclusive of all. As a result, this framework should be empirically examined to confirm on the validity and reliability of the constructs. 


\section{Acknowledgements}

The authors would like to thank the Secretariat of the SEA Regional Conference on SRI 2015 for sharing valuable inputs for the improvement of this article.

\section{References}

Badgley, C., Moghtader, J., Quintero, E., Zakem, E., Chappell, M. J., Aviles-Vazquez, K., ... \& Perfecto, I. (2007). Organic agriculture and the global food supply. Renewable Agriculture and Food Systems, 22(2), 86-108. DOI: 10.1017/S1742170507001640

Barah, B. (2009). Economic and ecological benefits of system of rice intensification (SRI) in Tamil Nadu. Small, 5(9).

Barrett, C. B., \& Moser, C. M. (2002). The system of rice intensification in practice: Explaining low farmer adoption and high disadoption in Madagascar. Water-Wise rice production, 8-11. DOI: 10.2139/ssrn.328641

Carswell, G. (1997). Agricultural intensification and rural sustainable livelihoods: a 'think piece'. Cassman, K. G. (1999). Ecological intensification of cereal production systems: Yield potential, soil quality, and precision agriculture. Proceedings of the National Academy of Sciences, 96(11), 5952-5959. DOI: 10.1073/pnas.96.11.5952

de Laulanié, H. (2011). Intensive rice farming in Madagascar. Tropicultura, 29(3), 183-187.

Devi, K. S., \& Ponnarasi, T. (2009). An economic analysis of modern Rice Intensification Technology and its adoption behaviour in Tamil Nadu. Agricultural Economics Research Review, 22(2009).

Dontsop-Nguezet, P. M., Diagne, A., Okoruwa, V. O., \& Ojehomon, V. (2011). Impact of improved rice technology on income and poverty among rice farming household in Nigeria: a Local Average Treatment Effect (LATE) approach. In contributed paper prepared for the 25th conference of the Centre for the Studies of African Economies (CSAE). St Catherine College, University of Oxford, UK (pp. 1-31).

Karki, S. (2010). System of Rice Intensification: an analysis of adoption and potential environmental benefits (Master thesis, Norwegian University of Life Sciences).

Katambara, Z., Kahimba, F. C., Mahoo, H. F., Mbungu, W. B., Mhenga, F., Reuben, P., ... \& Nyarubamba, A. (2013). Adopting the system of rice intensification (SRI) in Tanzania: A review. Agricultural Sciences, 2013. DOI: 10.4236/as.2013.48053

Khalil, T. M. (2000). Management of technology: the key to competitiveness and wealth creation. Boston: McGraw-Hill.

Kumar, R. M., Surekha, K., Padmavathi, C., Rao, L. S., Latha, P. C., Prasad, M. S., ... \& Viraktamath, B. C. (2012). Research experiences on system of rice intensification and future directions. Journal of Rice Research, 2(2).

Lampayan, R. M., Bouman, B. A., De Dios, J. L., Lactaoen, A. T., Espiritu, A. J., Norte, T. M., Quilang, E. J. P., ... \& Vicmudo, V. R. (2004). Adoption of water saving technologies in rice production in the Philippines. Food and Fertilizer Technology Center.

Matson, P. A., Parton, W. J., Power, A. G., \& Swift, M. J. (1997). Agricultural intensification and ecosystem properties. Science, 277(5325), 504-509. DOI: 10.1126/science.277.5325.504 
Namara, R. E., Weligamage, P., \& Barker, R. (2003). Prospects for adopting system of rice intensification in Sri Lanka: A socioeconomic assessment. Research Report 75. Colombo, Sri Lanka: International Water Management Institute.

Parasuraman, A., \& Colby, C. L. (2015). An updated and streamlined technology readiness index: TRI 2.0. Journal of Service Research, 18(1), 59-74. DOI: 10.1177/1094670514539730

Ragasa, C., Dankyi, A., Acheampong, P., Wiredu, A. N., Chapoto, A., Asamoah, M., \& Tripp, R. (2013). Patterns of adoption of improved rice technologies in Ghana. International Food Policy Research Institute Working Paper, 35.

Rao, I. V. Y. (2011). Estimation of efficiency, sustainability and constraints in SRI (System of Rice Intensification) vis-a-vis traditional methods of paddy cultivation in north coastal zone of Andhra Pradesh. Agricultural Economics Research Review, 24(2).

Stoop, W. A., Uphoff, N., \& Kassam, A. (2002). A review of agricultural research issues raised by the system of rice intensification (SRI) from Madagascar: opportunities for improving farming systems for resource-poor farmers. Agricultural systems, 71(3), 249-274. DOI: 10.1016/S0308521X(01)00070-1

Styger, E., Aboubacrine, G., Attaher, M. A., \& Uphoff, N. (2011). The system of rice intensification as a sustainable agricultural innovation: introducing, adapting and scaling up a system of rice intensification practices in the Timbuktu region of Mali. International Journal of Agricultural Sustainability, 9(1), 67-75. DOI: 10.3763/ijas.2010.0549

Tiffen, M., Mortimore, M., \& Gichuki, F. (1994). More people, less erosion: environmental recovery in Kenya. John Wiley \& Sons Ltd.

Tittonell, P. A. (2013). Farming Systems Ecology. Towards ecological intensification of world agriculture. Inaugural lecture upon taking up the position of Chair in Farming Systems Ecology at Wageningen University on, 16.

Uphoff, N. (2006). The system of rice intensification (SRI) as a methodology for reducing water requirements in irrigated rice production. Paper for International Dialogue on Rice and Water: Exploring Options for Food Security and Sustainable Environments, held at IRRI, Los Baños, Philippines, 241-278.

Uphoff, N. (2008). The system of rice intensification (SRI) as a system of agricultural innovation. Jurnal Ilmu Tanah \& Lingkungan, 10(1).

Vijayakumar, M., Ramesh, S., Chandrasekaran, B., \& Thiyagarajan, T. M. (2006). Effect of system of rice intensification (SRI) practices on yield attributes, yield and water productivity of rice (Oryza sativa L.). Research Journal of Agriculture and Biological Sciences, 2(6), 236-242.

von Braun, J., Puetz, D., \& Webb, P. (1989). Irrigation technology and commercialization of rice in the Gambia, effects on income and nutrition. Intl Food Policy Res Inst., 75. 